Monatsschrift f. Geburtshülfe u. Gynäkologie 1917;46:467-471

\title{
Bernhard Krönig †
}

Von O. Pankow

Am 29. Oktober 1917 hat Bernhard Krönig die Augen fur immer ge-schlossen, dieíe klaren, durchdringenden blauen Augen, deren heller Blick die Kraft und Stärke des Geistes erkennen ließ, der sie lenkte. Ein glänzender, scharf-kritischer Forscher, ein ungemein fesselnder, redegewandter Lehrer, ein prächtiger, warmherziger, gütiger Mensch ist mit ihm dahingegangen. Bis an sein Lebensende war Krönig ein Stürmer und Dränger. Selbst ideenreich wie kaum einer, fesselte ihn auch jede frerade neue Idee sofort mit aller Kraft. Mit seinem scharfen Verstande erkannte er sogleieh denKernpunkt der Sache, und es lockte ihn, das Neue nun auch für sein Spezialgebiet nutzbar zu machen. Mit stets frischer Begeisterung und immer gleichem jugendhchem Schwung griff er dann zu. Mühen und Anstrengungen scheute er nicht, und Hindernisse gab es für ihn nicht, wenn es gait, eine als richtig erkannte Idee durehzuarbeiten und durchzusetzen. Mit seiner ganzen Persönhchkeit trat er dann dafür ein, auch wenn die Allgemeinheit solchen Neuerungen noch ablehnend gegenüberstand oder ihnen n, ur zögernd folgte.

Es war selbstverständlich, daß dadurch oft genug der Widerspruch seiner Fachgenossen geweckt wurde und daß Krönig darum häufig im Mittelpunkt der wissenschaftlichen Kämpfe stehen mußte. Er scheute solche Kämpfe nicht, aber er führte sie stets vornehm und trug niemals Monatsschrift f. Geburt»hülfe u. Gynãkologie. Bd. XLVI. Heft 6. 31 468

Bernhard Krönig $\uparrow$.

zuerst den Streit auf das persönliche G·ebiet hinüber. Selbst eine durch -aus vornehme Natur, dachte er auch von seinen Gegnern vornehm. Oft klagte er daiüber, wie zuwider es ihm sei, wenn wissenschaftliche Streit -fragen persönlich genommen warden. Darum empfand er es zuweilen recht bitter, wenn er selbst nicht immer rein sachlich angegriffen wurde. Die trübsten Erfahrungen sind ihm da nicht erspart geblieben, die seine starke Natur doch manchmal mehr niedergediückt haben als alle an-strengende Arbeit und mehr, als er wohl merken lassen wollte. Am traurigsten waren diese Erfahrungen für ihn, als er in seiner Klinik die Röntgenbehandlung gutartiger Blutungen zu der so erfolgreichen Methode ausarbeitete, die uns heute gestattet, selbst die schwerst-entbluteten, nicht mehr operationsfäh, igen Kranken gefahrlos zu heilen. Da blieb es nicht nur bei wissenschaftlichen Widerspruch en, sondern weit über den Rahmen des wissenschaftlich, ja selbst des gesellschafthch Zulässigen ging das hinaus, was Krönig dam.als offen und versteckt über sich, seine Arbeit und seine Klinik hören mußte. ,,Da setzt m.an alles, selbst seinen guten Namen und seinen wissenschafthchen Ruf aufs Spiel, und das ist der Loh,П." So sagte er mir damals ein-n > .al voll Bitterkeit. Zum Glück war es ihm vergönnt, in dieser Frage den vollen Sieg seiner Arbeit zu erleben. Aber die wenigsten, die heute diese fertige Methode übernehmen und so erfolgreich anwenden, wissen es wohl, wie unendlich dornenvoll ihr Werdegang war und wie schwer die Kämpfe gewesen sind, die Krönig darum hat durchführen müssen. Sein offenbarer Sieg in dieser Frage gab ihm dann auch den Ansporn, das 
letzte große Ziel seines Strebens mit aller ihm eigenen unbeugsamen Energie ins Auge zu fassen, die Strahlenbehandlung des Krebses, an der sein regsamer Geist ungebrochen bis zum letzten Tage seines Lebens gearbeitet hat.

Außerordentlich bescheiden wie er war, geizte Krönig nicht nach äußeren Ehren. Er konnte auch ohne die Anerkennung seiner Mit-m.enschen leben. Es schmerzte ihn aber doch manchmal sehr, daß alle seine anstrengende Arbeit, sein redliches Mühen und sein bestes Wollen so verkannt und verurteilt wurden. Gewiß schoß er bei seinem Enthusiasm us und seinem spmdelndem Temperament manchmal über das Ziel hinaus. Ja es reizte ihn zuweilen geradezu, durch übertriebene Âußerungen den Widerspruch hervorzurufen. „Das regt wenigstens zur Nachprüfung und damit zur Arbeit i diesen Dingen an und fördert die Sache", pflegte er zu erwidern, 'wenn man nach solchenDiskussionen mit ihm darüber sprach. Wie sehr er aber auch manchmal durch solche Be-merkungen den Widerspruch der Kritik herausforderte, das Eine steht fest, daß Krönig in alien seinen Arbeiten niemals de $\prod$ Boden strenger Wissenschaftlichkeit verlassen hat. Nur wer das Glück gehabt hat, mit ihm Jahre hindurch zusammen zu arbeiten, kennt die ungeheure Mühe und die peinliche Sorgfalt, mit der Krönig an jede neue Aufgabe heranging - Erst wenn alles klar durchdacht war, fing er mit einfacher Eragestellung seine Vorversuche an, die •stets mit peinlich, er Methodik durchgeführt werden mußten. „E $1 / 8$ e neue Idee kommt nicht plötzlich, sondern mühevoll wird Baustein auf Bau $\delta \mathrm{te}^{1 / 8} \mathrm{~g}$ gehäuft." Das schrieb er selbst einmal, und das kennzeich.net seine Arbeitsart. Von großem allgemeinen Wissen und umfassender Belesenheit, kannte er doch stets

Bemhard Krönig †. 469

die Grenzen seines Könnens. Sobald irgend ein Punkt seiner Arbeit Fragen aus einem ánderen Gebiet anschnitt, sei es physikalisch, oder chemisch, anatomisch, physiologisch. oder klinisch, holte er stets den Rat des Fachmannes ein. Er litt es nicht, daß seine Mitarbeiter von die $>$ ser Gewohnheit abwichen. Dadurch gestaltete sich das wissenschaft-liche Ai'beiten an seiner Klinik auch so besonders interessant. Darum aber waren auch seine Schüler stets durchdrungen von dem Wert seiner Forschungen, und sie vertrauten ih $\prod$ i bUndlings.

Bei seiner ungeheuren Arbeitskraft, die eine Ermüdung kaum kannte, stellte er auch hohe Anforderungen an seine Schüler, und' es war nicht immer leicht, Krönigs Assistent zu sein. Aber das war gerade das Hinreißende und Packende an ihm, daß er ohne äußeren oder in,neren Zwang allein durch die Kraft seiner Persönlichkeit seine Schüler zur freudigen Mitarbeit hinriß. Dabei verlangte er keine sklavische An-erkennung seiner Ideen. Wie er selbst sich bei seinen wissenschaftlichen Forschungen frei niachte von dem jurare in verba $\mathrm{n}$ agistri so Verlangte er es auch nicht für sich selbst. In freimütiger Kritik nahm er jeden Widerspruch hin. Allerdings verlangte er dann stets eine logische Be-gründung, und er haßte es, wenn ihm mit Schlagworten widersprochen wurde. Erkannte er die Berechtigung des Widerspruchs an, dann bestand er auch nicht auf seiner Ansicht, ja er freute sich, wenn er den jungen Assistenten die Freude des Rechtes dem Chef gegenüber lassen konnte. Diese Vorurteilslosigkeit zeigte sich auch in seinem ganzen wissenschaftlichen Werdegang.

Selbst ein glänzender, kunstvoller Operateur, der uns zusammeu mit Döderlein die prachtvolle operative Gynäkologie geschenkt hat, und ein freudiger und begeisterter dazu, scheute er sich nicht, die operative Therapie einzuschränken oder preiszugeben, wenn er zu der Ansicht gekommen war, daß andereMethoden Besseres leisteten und seinen Kranken größere Lebenssicherheit gaben. Mit Unrecht hat man Krönig so oft einen radikalen Operateur genannt. Gewiß zog er, wenn er einmal operieren mußte, bei manchen Kxankheiten, wie beim Karzinom und den Myomen, die radikalen Operationen vor. Niemals aber war Krönig ein radikaler 
Operateur in dem Sinne, daß er seine Indikationen leicht stellte und viel operierte. Das Gegenteil war der Fall. Mit vollem Recht konnte er einmal von sich sagen, daß er eigentlich gar nicht wisse, wo-durch er in den Ruf eines radikalen Operateurs gekommen sei. War er es doch, der mit als erster in Deutschland für die Einschränkung der operativen Behandlung der entzündlichen Adnexerkrankungen eintrat und der eine möglichste Zurückhaltung bei der Einleitung der prophy-laktischen Wendung, der hohen Zange und der künstlichen Frühgeburt in der Behandlung des engen Beckens empfahl. Er war es, der zuerst in Deutschland in großem Maßstabe die operative Behandlung der Myome und der hämorrhagischen Metropathie durch das unblutige Röntgenverfahren ersetzte. Nicht zum geringsten war es auch sein Verdienst, daß er durch seine Arbeiten über die Bedeutung der funk-tionellen Nervenerkrankungen zur Gynäkologie dazu beigetragen hat, daß die Operationen der Retroflexio uteri mobilis, der kleincystischen Degenerationen der Ovarien, der Emmetschea. Risse, der Erosionen usw. erheblich eingeschränkt wurden.

$31^{*}$

\section{Bernhard Krönig $\uparrow$.}

Ebenso vorurteilslos wie als Operateur war er aber auch sonst. Die Ausgestaltung der Narkose

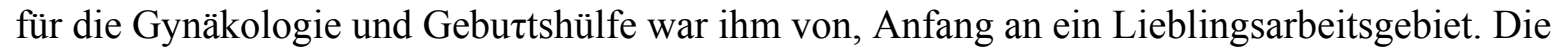
Vervollkommnung der Mischnarkose durch die Annahme des Braunschen und dann durch die Einführung des Roth-Draegerschen Apparates, ihre raschere Ein-leitung durch Gaben von Lachgas und $\mathrm{C}^{1} / 8$ loräth, yl, ihre Komb¹/8ation mit Veronal, Morphium- Skopolamin oder Pantopon und Narkophin macb, te er sich zur Aufgabe und freute sich an ihren Erfolgen. Ohne zu zaudern aber gab er das alles preis, als er zu der Überzeugung karn, daß die Lumbal-, Sakral- und die Leitungsanästhesie leistungsfähiger und lebenssicherer sein würden. ,,Das Bessere ist der Feind des Guten", das war sein Leitmotiv in solchen Dingen. Das Vorhandene auszu-arbeiten und durch Wertvolleres zu ersetzen, das war sein dauerndes Streben.

Unendlich groß ist deshalb auch die Arbeit, die Krönig geleistet hat. $\mathrm{Zu}$ alien Fragen nahm er Stellung, und in vielen schaffte er gnrnd-Iegend Neues. Seine Arbeit über die Bakteriologie des weiblichen Ge-nitalapparates, über die Beziehung der funktionellen Nervenkrankheiten zur Gynäkologie, seine Arbeiten über die Narkose in der Gynäkologie und den Dämmerschlaf in der Geburtshülf e und zuletzt über die Strahlen-behandlung der Blutungen gutartiger und bösartiger Neubildungen, das $\mathrm{s}^{1} / 8 \mathrm{~d}$ nur Marksteine auf seinem Lebenswege. Sie zeigen ohne weiteres schon, welch eine ungeheure Arbeitskraft dazu gehörte, das alles zu bewältigen und an alien diesen Dingen gestaltend mit tätig zu sein. Wer aber die Mühseligkeit aller dieser Eorschungen Krönigs mit erlebt hat, erst der kann seine gewaltige Arbeit richti\$ erkennen und sie ganz würdigen. Es ist die Tragik seines Geschicks, daß er die Anerkennung seiner Riesenarbeit vielfach nicht gefunden hat. Wer aber den Ernst seines wissenschaftlichen Forschens kannte, der glaubte an ihn, und der kann heute an seinem frischen Grabe hoffen, daß عeine mühevolleLebensarbeit nicht vergeblich war und daß noch ganze Generationen nach ihm die Früchte von den Bäumen pflücken werden, die er gepflanzt hat.

Eigenartig und immer von neuem fesselnd wie als Forscher war Krönig auch als Lehrer. Mit klangvollem Organ und einer seltenen Rede-gewandtheit begabt, war er ungemein klar im Ausdruck und tiber-zeugend in der Darstellung. Die nüchternsten Themen wußte er er-frischend und temperamentvoll abzuhandeln. Sein köstlicher Humor würzte, zuweilen etwas drastisch, seine Rede. Er liebte es nicht, im Kolleg nur vorzutragen. Stets suchte er seine Hörer zum Mitdenken zu zwingen. Zwischenfragen, die er im ganzen Auditorium herumstreute, sorgten dafür, daß er das auch erreichte. Den Unterricht der Studenten seminaristisch auszugestalten war 
sein Ziel. Dabei schonte er die An-fänger und die Unwissenderen mit feinem Takt, damit ihnen nicht durch eine Bloßstell-ung die Lust am Kolleg genommen würde. War der Ab-grund, in den er sah, einmal gar zu tief, dann half ihm wieder sein treff-licher Witz und sein Humor, dem Tadel die kränkende Schärfe zu nehmen. Darum verehrten ihn auch seine Studenten. Ihm selbst war die ständige Berührung mit der heranwachsenden Jugend immer wieder eine Erfrischung, und er liebte es besonders, wenn er ihr im zwanglosei\%o Bernhard Krönig †.

471

Verkehr außerhalb der Klinik auch menschlich natter kommen konnte. Dazu bot ihm seine große Liebe zur Natur nnd zum Sport grade in Freiburg die beste Gelegenbeit. Wenn er mit den Schneeschuhen unter den Füßen sich auf den Höhen des Schwarzwaldes herumtummeln konnte, dann war er ganz glücklich. Dort holte er sich an den Feiertagen die Kraft und Freude zur neuen anstrengenden Wochenarbeit. Dort war er dem jüngsten Schüler Kamerad und abends am traulichen Kamin der witzsprühende Unterhalter, frei vön Stand und Rang und Würden, nur der frohe Mensch dem Menschen gegenüber.

Diese große Liebe zur Natur, die in Krönig wolinte, offenbarte schon seine Warmherzigkeit und die Tiefe seines Gemütes, die er oft nich,t erkennen lassen wollte. Wer ihn aber näher kannte, der wüßte, wie gütigen Sinnes er war. Er war ein stiller Woh,ltäter, der aber niemals wollte, daß man darüber sprach, wenn man Zeuge solcher Dinge ge-worden war, und der es auch mit Humor aufnahm, wenn er einmal merkte, daß man seine Gutmütigkeit mißbraucht hatte. Im Gruncie fröhlichen Gemüts und ein Lebensbejaher, hatte er die Gabe, seinen Kranken oft durch ein einziges Wort die verlorene Lebensfreude und das Vertrauen auf die Genesung wiederzugeben. Seine Patientinnen schwärmten deshalb für ihn und vertrauten ihm blind. Ein stets·freund-hches, Hebenswürdiges und verständnis voiles Eingehen auf ihre Klagen, wie er selbst es den Kranken aller Klassen gegenüber hatte, verlangte er auch von seinen Assistenten. Jeden suchte er zu neuen Arbeiten heranzuziehen und zu fördern. Für jeden hatte er das gleiche Interesse und für alle stets ein freundlich.es Verstehen in all' den kleinen und großen Nöten, die ihnen widerfuhren. Sein allem Kleinlichen so ab-holdes Wesen kannte keine Launen, die der Assistent fürchten mußte. Er wollte ihnen niemals der strenge, unnahbare Chef sein, sondern nur der kameradschaftliche Mitarbeiter und Vorarbeiter. Darum war es auch durch lange Jahre hindurch so schön, sein Assistent zu sein.

So schwebt uns heute Bernhard Krönigs Bild vor als das eines vor-urteilslosen, streng wissensehaftlichen Forschers, eines begeisternden, klaren und fröhlichen Lehrers, eines guten und warmherzigen Menschen.

Wer ihn nicht näher geka ${ }^{3} / 8$ it hat, der wird doch seine Arbeitskraft bewundern und wenigstens den Toten und seine Werke hoch achten müssen'

Wer ihn aber näher gekannt hat, der mußte ihn verehren und lieben

und der wird diesen goldenen Menschen nicht Vergessen, von dem man

mit seltenem Recht sagen kann, daß er für uns alle viel zu früh dahin-

gegangen ist. ö. Pankow.

Worte beim Wiederbeginn der klinisehen Vorlesungen naeh dem Tode von Herrn Geheimrat Professor Dr. B. Krönig.

Ich spreche heute nach dem Tode unseres verehrten und geliebten Chefs und Lehrers, Herrn Geheimrat Krönig, zum ersten Male wieder zu Ihnen an der Stätte, von der aus er Ihnen, uns Assistenten und vielen Hunderten von Schülern sein ärztliches Wissen, Können, seine Er- 
fahrungen und Ideen als Lehrer in der Klinik mitgeteilt hat. Wir haben alle gemeinsam einen

gleich großen, herben und unersetzlichen Verlust

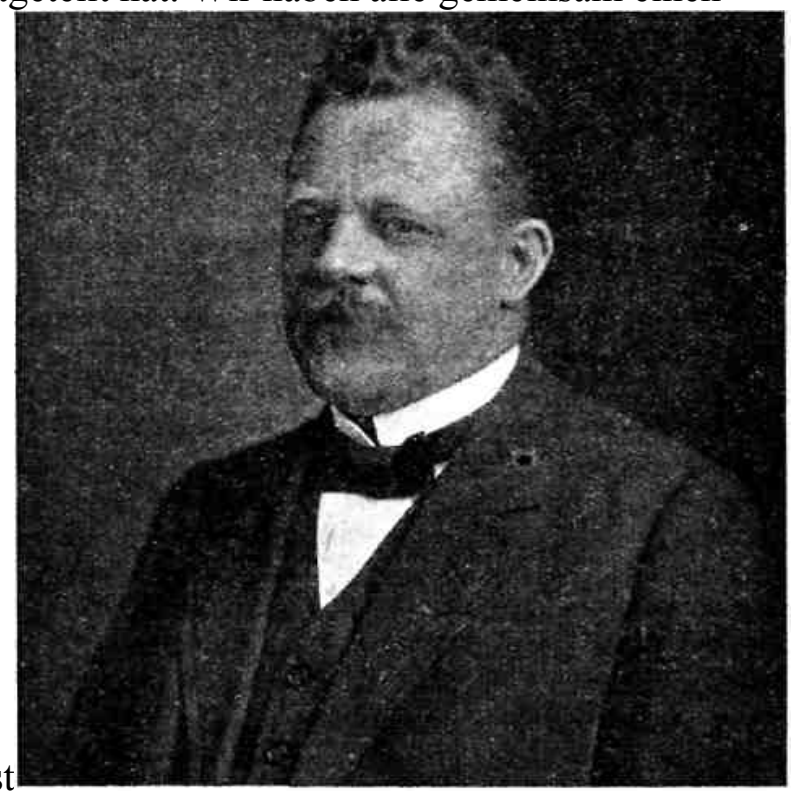

